\title{
Estratégia de desenvolvimento e as três frentes de expansão no Brasil: um desenho conceitual *
}

\author{
Ricardo Bielschowsky **
}

\begin{abstract}
Resumo
O artigo pretende ajudar a organizar, conceitualmente, o debate brasileiro sobre desenvolvimento, em sua dimensão econômica. Desenha uma estratégia de desenvolvimento para o Brasil com base na ideia de existência de três frentes de expansão, movidas pela demanda - três "motores do investimento": consumo de massa, recursos naturais e infraestrutura. Enfatiza a relevância de se acionarem dois "turbinadores" desses motores do desenvolvimento (inovação tecnológica e reativação de encadeamentos produtivos tradicionais). Argumenta, também, que a fórmula corresponde a um padrão viável de expansão econômica a longo prazo - tal como, no passado, deu-se com o processo de industrialização.
\end{abstract}

Palavras-chave: Estratégia de desenvolvimento; Frentes de expansão; Consumo de massa; Recursos naturais; Infraestrutura.

\section{Abstract \\ Development strategies and the three fronts of expansion in Brazil: a conceptual design}

The article aims at helping to provide a conceptual framework for the Brazilian debate on economic development strategies. It designs a strategy on the basis of the idea of the existence of three demandled "growth fronts," or three "engines of investment": mass consumption, natural resources and infrastructure. The article stresses the relevance of putting into action two "turbo-chargers" of these three engines of investment; namely technological innovation and the recuperation of traditional productive chains. Finally, the author argues that this formula can be a viable long term pattern of economic growth, analogous to that which occurred in the past as a result of industrialization.

Keywords: Development strategies; Expansion fronts; Mass consumption; Natural resources; infrastructure.

JEL O10.

\section{Introdução}

Este ensaio apresenta um desenho conceitual para a elaboração de uma estratégia de desenvolvimento para o Brasil.

\footnotetext{
* Ensaio escrito no âmbito do projeto do Ipea sobre "Agenda Desenvolvimentista Brasileira e sua Inserção Global".

${ }^{* *}$ Professor do Instituto de Economia da Universidade Federal do Rio de Janeiro (IE/UFRJ), Rio de Janeiro, RJ, Brasil. E-mail: ricardo.bielschowsky@gmail.com.
}

Economia e Sociedade, Campinas, v. 21, Número Especial, p. 729-747, dez. 2012. 
O ponto central aqui apresentado é o de que o Brasil tem o privilégio de possuir ao mesmo tempo três poderosas frentes de expansão, três "motores" do desenvolvimento, um conjunto que poucos países do mundo possuem:

- Um amplo mercado interno de consumo de massa- que será tanto mais amplo quanto melhor vier a ser a distribuição da renda. Também, uma estrutura produtiva potencialmente capaz de vir a realizar localmente boa parte da produção em larga escala correspondente, nos setores primários, industriais e de serviços, sem prejuízo de ampliar as exportações;

- Uma forte demanda nacional e mundial por seus abundantes recursos naturais;

- Perspectivas favoráveis quanto à demanda estatal e privada por investimentos em infraestrutura (econômica e social).

Se os impulsos à expansão da capacidade produtiva derivados dessas três correntes de demanda efetiva vierem a ser adequadamente traduzidos em expansão do investimento no país, o desenvolvimento brasileiro poderá ser vigoroso nas próximas décadas.

Observe-se que está propositadamente ausente, na formulação, a ideia frequente de que exportações de bens industriais possam ser um motor de investimento em si mesmos. Isso porque, no Brasil, elas atuam como complemento à demanda gerada pelo mercado interno. De fato, como se mostra em mais de um estudo sobre os determinantes do investimento brasileiro, as decisões de investir nas empresas industriais sediadas nos países acontecem essencialmente em função do mercado interno e só de forma complementar visam ao mercado internacional, conforme Bielschowsky (2002). As exceções, como a dos aviões da Embraer, apenas confirmam a regra ${ }^{1}$.

Os investimentos nessas três frentes de expansão serão tão mais volumosos e mais mobilizadores da atividade produtiva e do emprego no país quanto mais amplos forem os processos de inovação e os encadeamentos produtivos que o país for capaz de gerar nas três frentes.

Devidamente "turbinados" ("potenciados") por inovações tecnológicas e pela recuperação de encadeamentos produtivos fragilizados, os três motores do crescimento com transformação estrutural representam uma rara oportunidade de desenvolvimento a longo prazo da economia brasileira. Mal turbinados, sua contribuição potencial tenderá a ser, em grande medida, desperdiçada.

(1) Em outras palavras, ao invés de crescer pela via das exportações (modelo export-led growth), ocorre o oposto:o mercado interno grande permite a conquista de capacidade para exportar por meio de ganhos de escala e de produtividade conferidos pelo mesmo (growth-led export, na feliz expressão de Colin Bradford). 
Nessa formulação, a inovação tecnológica tem um papel fundamental. Sua função essencial reside no fato de que, se o processo de inovação expandir-se de modo adequado, poderá turbinar poderosamente as três engrenagens do investimento. Permitirá transformar em núcleos estruturantes da economia nacional várias atividades produtivas ainda inexistentes ou, em fase incipiente - como, por exemplo, o "Pré-sal" e a utilização sustentável da biodiversidade - e inaugurar ou reforçar a existência de encadeamentos produtivos com alta densidade tecnológica. Isso significará adensar as três frentes de expansão, ampliar seus efeitos multiplicadores de renda e emprego e reduzir a vulnerabilidade externa da economia brasileira.

Mesmo assim, a inovação não é aqui considerada como uma frente de expansão em si mesma, já que a atividade de $\mathrm{P} \& \mathrm{D}$ no país ainda não está suficientemente inserida nas estratégias de expansão das empresas. Se isso vier a ocorrer, como se dá nos países mais desenvolvidos, a inovação poderá tornar-se um quarto motor do desenvolvimento a longo prazo.

O segundo "turbinador" dos motores do desenvolvimento consiste no fortalecimento de encadeamentos produtivos tradicionais, aí incluída a recuperação dos que se fragilizaram por circunstâncias macroeconômicas internas e/ou internacionais adversas e que são potencialmente competitivos. Nesse campo, ainda que o processo inovador tenda a ser relevante - poucos setores de atividade produtiva moderna são intocados pelo progresso técnico avassalador dos tempos atuais - as decisões de investimento inclinam-se a depender menos de inovações tecnológicas do que de outros incentivos à rentabilidade como taxas de câmbio mais favoráveis, demanda de governo e outras políticas industriais que possam contribuir para a reconstituição da competitividade perdida.

A proposição conceitual das frentes de expansão tem a virtude de, a princípio, permitir que se ponha o foco do planejamento do desenvolvimento econômico sobre o volume e a composição setorial e tecnológica dos investimentos, ou seja, são as variáveis que definem o crescimento e o aumento de produtividade a longo prazo. Trata-se de um enfoque ao mesmo tempo keynesiano, kaldoriano e estruturalista. Inspira-se em Keynes (1973) porque toma o investimento como resultado de estímulos de demanda efetiva, em Kaldor (1989), porque considera o progresso técnico e o learning by doing processos que acompanham o investimento gerado por expansão de demanda e ajudam a alimentar os rendimentos crescentes de escala que permitem o aumento de produtividade. É estruturalista porque, ao centrar a análise no investimento e nas transformações estruturais que suscita, orienta a discussão diretamente ao "estilo" de desenvolvimento desejado e historicamente viável (Pinto, 1976).

Este breve ensaio limita-se à dimensão econômica da estratégia, não abordando suas demais dimensões críticas como educação, sustentabilidade 
ambiental, integração e harmonia regional e territorial, inserção internacional e reformas institucionais. As questões cruciais relativas à distribuição de renda, pobreza, inclusão e demais políticas sociais tampouco são tratadas, a não ser em sua integração com o projeto econômico pela via do modelo de crescimento com redistribuição de renda por produção e consumo de massa.

Além disso, na dimensão econômica, por razões de espaço, também não se abordam questões pertinentes à macroeconomia e ao financiamento para o desenvolvimento, apesar de serem elementos constitutivos essenciais de qualquer estratégia nacional de desenvolvimento. Assim, não se discute, por exemplo, o problema do uso por muitos anos no Brasil do binômio "juros elevados taxas de câmbio apreciadas", prejudiciais à competitividade, aos investimentos e à diversificação produtiva da economia brasileira. Também não se discute o provável enfraquecimento do balanço de pagamentos em conta-corrente resultante desse binômio e o perigoso recurso ao endividamento - à "poupança externa" - uma receita que a história do país ensina a evitar a todo custo, por seus efeitos deletérios sobre a autonomia para crescer a médio e longo prazos ${ }^{2}$.

$\mathrm{O}$ atual contexto de crise financeira mundial recomenda uma última observação introdutória, ou seja, a de que a crise reforça a importância de se discutir o desenvolvimento brasileiro. Primeiro, porque obriga a que se pense em graus de autonomia relativa para crescer. Segundo, porque a crise é simultânea ao deslocamento do centro dinâmico mundial à China e essa mudança histórica impõe uma escolha definitiva para o Brasil: aceitar passivamente a "reprimarização" de sua economia ou, ao contrário, aproveitar a redução da vulnerabilidade externa resultante da valorização das exportações de matérias primas - condição praticamente ausente no Brasil, ao menos, desde a arrancada industrializante em 1930 - para fortalecer não só as atividades primárias e os serviços, mas também o setor industrial e os impulsos à inovação, ao progresso técnico e ao crescimento inerentes às atividades desse setor.

O artigo está dividido em três partes, além desta introdução e da conclusão. Primeiro, contextualiza a proposição central sobre os três motores do desenvolvimento e seus "turbinadores" nos marcos da evolução do debate brasileiro sobre desenvolvimento. Em seguida, há uma breve apreciação sobre os três motores. Por último, analisa os dois "turbinadores", ou seja, as inovações viabilizadoras dos investimentos em segmentos tecnologicamente nobres da atividade econômica e a recuperação e ampliação dos encadeamentos produtivos tradicionais.

(2) Há uma série de autores que se dedicam no Brasil ao tema da macroeconomia para o desenvolvimento, entre eles os que escreveram sob a inspiração da ideia de um "novo-desenvolvimentismo", lançada no Brasil alguns anos atrás. Ver, por exemplo, Sicsu e outros ( 2005) e Bresser-Pereira (2010). 


\section{0 estágio atual do debate brasileiro sobre desenvolvimento}

A acelerada industrialização que ocorreu entre 1930 e 1980 foi, a partir da década de 1950, conduzida pelo Estado e acompanhada pela hegemonia da ideologia desenvolvimentista, que preconiza o suporte estatal aos investimentos necessários à transformação estrutural da economia (Bielschowsky, 1995 e Bielschowsky; Mussi, 2005). Foi a era desenvolvimentista, em que predominou na sociedade brasileira, segundo a feliz conceituação de Castro (1993), uma "convenção do crescimento".

A partir de 1980, essa ideologia perdeu a capacidade de influenciar que havia tido nas décadas prévias. A perda foi o reflexo, no plano ideológico, da evolução econômica, em particular da aceleração inflacionária, da profunda e prolongada crise externa e fiscal, do consequente enfraquecimento do Estado desenvolvimentista e da consequente estagnação. A instabilidade macroeconômica e a fragilização da máquina estatal dedicada às tarefas desenvolvimentistas impediram que eventuais projetos de desenvolvimento prosperassem e inibiram a reflexão sobre desenvolvimento econômico.

Até então, o liberalismo havia ocupado durante várias décadas uma posição secundária na vida socioeconômica brasileira. É a ideologia que considera, no essencial, a alocação eficiente de recursos só podendo dar-se pela livre ação das forças de mercado, o volume de recursos destinado ao investimento dependendo de decisões dos consumidores quanto à poupança desejada e a intervenção do Estado reduzindo a eficiência econômica, o aumento de produtividade e o crescimento. Sua influência decrescente a partir de 1930 no Brasil refletiu a implementação com êxito do projeto de industrialização, bem como a força do paradigma keynesiano entre o pós-guerra e os anos 1970 em todo o mundo ocidental. Quando a hegemonia desenvolvimentista no Brasil dissolveu-se, na década de 1980, refletindo o vazio de projetos e de políticas de investimento e crescimento que passou a predominar no país, abriu-se espaço à afirmação da corrente neoliberal, com especial intensidade a partir do final da década de 1980.

Um estudo detalhado da evolução ideológica brasileira no campo da economia nos anos 1990 - ainda por ser realizado - possivelmente encontrará rápida ascensão da ideologia neoliberal, em especial na "mídia" e no mundo das finanças. Talvez, surpreenda-se com o fato de que, curiosamente, as duas principais formas de liberalização do marco regulatório da economia brasileira, a comercial e a financeira, foram anteriores ao amadurecimento do neoliberalismo no plano ideológico, já que ocorreram durante o confuso contexto da alta inflação, quando o neoliberalismo

ainda amadurecia no país, nos primeiros anos da década de 1990. É provável que identifique, também, a conquista de uma hegemonia da ideologia neoliberal no (curto) período 1995-1998 - entre os efeitos do Plano Real e os efeitos das crises asiática, russa, brasileira e argentina - em que o Congresso Brasileiro recebia um 
"rolo compressor" político e ideológico para aprovação de reformas, destacando-se a privatização de grandes empresas estatais.

No plano do pensamento econômico produzido no mundo acadêmico, uma boa hipótese de trabalho seria a de que tenha predominado nas últimas décadas - e mesmo durante o referido quadriênio - certo equilíbrio entre, por um lado, o pensamento ortodoxo em matéria macroeconômica e neoliberal em matéria de alocação de recursos e, por outro lado, a heterodoxia macroeconômica e o desenvolvimentismo. Ao mesmo tempo, é razoável supor que, nas três décadas posteriores a 1980, nem mesmo o declínio da ideologia desenvolvimentista e o predomínio do foco às questões macroeconômicas tenham conduzido a uma menor produção acadêmica de orientação desenvolvimentista sobre as questões pertinentes ao desenvolvimento, comparativamente às décadas prévias.

Ao contrário, é mesmo provável que a quantidade de trabalhos na temática do desenvolvimento - estrutura produtiva, progresso técnico, desenvolvimento regional, inclusão social, pobreza e distribuição de renda, meio ambiente, institucionalidade etc. - tenha sido muito superior ao período anterior. A suspeita deve-se a uma série de razões, entre as quais a forte ampliação do número de centros acadêmicos e professores em tempo integral de Economia e demais ciências sociais e a sobrevivência de uma série de instituições governamentais da era desenvolvimentista que preservaram suas missões originais como o Instituto de Pesquisa Econômica Aplicada (Ipea), o Banco Nacional de Desenvolvimento Econômico e Social (BNDES), a Financiadora de Estudos e Projetos (Finep), as secretarias estaduais de planejamento etc.

Trata-se, porém, de uma fase de produção intelectual nas questões do desenvolvimento muito distinta da anterior. A literatura desenvolvimentista prévia a 1980 tinha como foco um padrão comportamental da economia brasileira que era possível identificar com razoável clareza. A temática debatida circunscrevia-se, em essencial, a processos históricos inscritos em uma lógica de transformação econômica perfeitamente identificada e entendida como de longo prazo: a industrialização. Foi, portanto, de modo geral, uma produção intelectual engajada na análise e discussão de tendências sobre as quais parecia haver certa previsibilidade. Também, dinamizada por formulações e debates entre visões favoráveis e contrárias sobre a forma como estavam ocorrendo e sobre as políticas econômicas aplicadas.

Quando aquele padrão de desenvolvimento desarticulou-se na entrada dos anos 1980, por força da crise da dívida e instalaram-se aguda instabilidade macroeconômica e relativa estagnação no nível de atividade, passaram a prevalecer incertezas e perplexidades com relação às tendências a médio e longo prazos dos setores produtivos. A produção de ideias passou a refletir uma evolução histórica desprovida de referência a algum padrão de desenvolvimento claro e, 
consequentemente, desprovida de referência a alguma estratégia de desenvolvimento e a possíveis políticas governamentais correspondentes. $O$ fato de que isso transcorreu em meio a um processo de globalização e a uma intensa revolução tecnológica - por certo, discutidos no país - ampliou as incertezas.

Em resumo, parecem ter faltado ao pensamento sobre desenvolvimento depois de 1980 suas duas tradicionais referências organizadoras, ou seja, um padrão de desenvolvimento e as estratégias e políticas governamentais de longo prazo. A literatura sobre desenvolvimento, embora profícua em volume, parece ter apresentado, por essa razão, tendência à baixa sistematicidade, descontinuidade e dispersão ${ }^{3}$.

Nos últimos anos, houve uma novidade importante, ou seja, as perspectivas de maior estabilidade macroeconômica abertas pela guinada chinesa por importações de matérias primas, cujo impacto favorável ao balanço de pagamentos brasileiro ocorreu a partir de 2002/3 - coincidentemente, mais ou menos em simultâneo com o início do governo Lula. A mudança parece representar solo fértil para uma nova etapa de discussões sobre o desenvolvimento.

Ainda que os progressos em tal direção ainda tenham sido relativamente lentos, já é possível discernir alguns avanços na última década, tanto na discussão sobre uma macroeconomia para o desenvolvimento - importante tema não tratado neste artigo, como observado na seção introdutória - quanto na apresentação de ideias sobre desenvolvimento desde o ponto de vista da alocação de recursos para transformação estrutural da economia, que é o tema que aqui nos ocupa ${ }^{4}$.

Os candidatos a organizadores de um projeto nacional de cunho desenvolvimentista no período foram três: i) Crescimento com redistribuição de

(3) Há de reconhecer que, ao longo desses trinta anos, podem-se encontrar no pensamento econômico brasileiro várias incursões no plano das definições de novos rumos econômicos no país, tanto na área acadêmica como no governo. Podem até ter sido fugazes e fadadas ao esquecimento, mas, embora atropeladas por crises recorrentes, não foram inexistentes. O reconhecimento, por exemplo, de que se transitava a um novo ciclo tecnológico mundial - a era da eletrônica - permeou toda uma literatura que conclamava esforços de reorientação do desenvolvimento brasileiro do ciclo metal - mecânico ao ciclo eletrônico.

(4) Esse último tema tem sido tratado, sobretudo no âmbito do governo federal. Em um trabalho recente sobre o planejamento do desenvolvimento brasileiro, Gimenez e Cardoso (2012) identificam e analisam cerca de 30 documentos oficiais, redigidos entre 2003 e 2010, a grande maioria com orientação nitidamente desenvolvimentista. Essa literatura governamental inclui tanto documentos de planejamento de natureza temática (meio ambiente, direitos humanos etc.) e setoriais (indústria, energia etc.) como documentos mais gerais, orientados ao desenvolvimento como um todo. Nesses últimos, é possível verificar que, referindo-se à condução do processo de transformação da economia brasileira a médio e longo prazos, três conceitos rivalizaram com a perspectiva neoliberal - a qual, diga-se de passagem, teve sua última aparição importante em documentos do governo federal em um texto publicado pelo Ministério da Fazenda (2003), redigido pela Assessoria Econômica do então Ministro Pallocci, que propugnava a introdução de reformas institucionais de inclinação neoliberal como ordenadora de um novo projeto nacional. 
renda pela via do consumo de massa (PPA 2004-2007); ii) Investimentos em infraestrutura (PAC); iii) Inovação (PITCE, PDP, Plano Brasil Maior) ${ }^{5}$.

Cada uma das três formulações pretendia-se portadora da fórmula de condução do desenvolvimento e foi apresentada com pouca interação com as outras duas. Não chegaram a tornar-se rivais e, até por vezes, houve o reconhecimento explícito de complementariedades, mas nenhuma das três explorou uma integração com as demais e nenhuma delas foi efetivamente vencedora no que se refere a estabelecer um novo projeto nacional, reconhecido como tal. O resultado de todo esse esforço foi o de que, apesar de avanços quanto à introdução das três peças básicas constitutivas de uma estratégia de desenvolvimento e de avanços com relação a outras peças importantes - setoriais e temáticas - o desenho claro de uma nova estratégia permaneceu por ser realizado: as peças mantiveram-se dispersas em um pensamento relativamente difuso e fragmentado.

\section{Os três motores do desenvolvimento econômico: consumo de massa, recursos naturais e infraestrutura}

A proposta que se segue pretende reordenar as principais peças soltas, aderindo-as ao contexto histórico atual e adicionando o ingrediente básico da nova realidade mundial, a forte expansão da demanda por recursos naturais.

Antes de prosseguir, cabe uma observação metodológica. Salvo em circunstâncias muito especiais como as de uma revolução com mudança de regime político ou de uma guerra de libertação nacional, a identificação, o desenho e a implementação por uma sociedade e por seus governos de uma estratégia nacional de desenvolvimento - e de sua institucionalidade e suas políticas - dão-se de forma gradual. Elas ocorrem como resultado de acontecimentos, pressões, articulações e conflitos econômicos e políticos que a própria evolução histórica de cada país vai promovendo e revelando.

Esse foi o caso brasileiro do planejamento e das políticas em favor da industrialização no Brasil, durante a era desenvolvimentista. A expansão da indústria vinha acontecendo espontaneamente, diante da crise internacional dos anos 1930, da guerra mundial e da relativa anormalidade que a ela se seguiu. No período 1930-45, foram implantadas algumas mudanças institucionais relevantes, preparadoras do futuro. Foi, no entanto, somente na entrada dos anos 1950, com o segundo governo Getúlio Vargas, que se introduziu uma série de reformas institucionais destinadas a conduzir os investimentos estimulados pela demanda doméstica de produtos

(5) Ver ao final do texto as referências bibliográficas, listadas em "Brasil", vários anos. Observe-se que, em 1999, o Plano Plurianual 2000-2003 do governo federal apresentou outro candidato, logo abandonado: a noção de integração territorial por meio de grandes investimentos em infraestrutura voltados à formação de corredores de exportação (os “eixos de integração"), acompanhados da ideia de multiplicação de parcerias público-privadas. 
industriais e a infraestrutura correspondente. $O$ planejamento e as políticas industrializantes empregados daí em diante destinaram-se a conferir, ao processo de industrialização, maior velocidade e eficiência ${ }^{6}$.

Analogamente, no caso da economia brasileira atual, estão presentes as três mencionadas engrenagens de demanda efetiva - consumo de massa, recursos naturais e infraestrutura. Bem aproveitadas no que se refere a incentivos ao investimento e bem turbinadas, converter-se-ão em "motores do investimento" com duração e impacto de longo prazo.

Distintas motivações históricas inscreveram esses três motores na lógica central de operação da economia brasileira. Como se sabe, dizem respeito à expansão no consumo popular desde meados dos anos 2000, motivada pela recuperação do crescimento, por melhorias distributivas na renda e por ampliação do crédito; à expansão da demanda asiática por recursos naturais e à ampliação dos investimentos da Petrobrás; no caso de infraestrutura, à retomada dos investimentos públicos. Cabe assinalar aqui que a escolha das três frentes de expansão na presente formulação não é arbitrária, ela obedece a evidencias empíricas que se tem sobre o atual funcionamento das economias brasileira e mundial e ao fato de que as perspectivas de êxito a longo prazo mostram-se potencialmente favoráveis - a depender, por suposto, dos desdobramentos da economia mundial atualmente em crise.

Trata-se, ainda, de uma mera possibilidade histórica, de um processo ainda em formação, cujo detalhamento e correspondente costura política entre os atores econômicos, sociais e políticos relevantes ainda se encontram em fase relativamente inaugural - e por isso mesmo pouco clara, do ponto de vista ideológico. É razoável, no entanto, propor essa formulação à sociedade como instrumento ordenador da reflexão sobre desenvolvimento, na medida em que se dirige a um processo histórico viável, por pelo menos duas razões. Primeiro, porque se assenta em mecanismos de expansão da atividade produtiva que, no momento atual, se encontram perfeitamente inscritos na lógica de operação da economia brasileira, em forma análoga ao que no período 1930-1980 ocorreu com o processo de industrialização. Segundo e não menos importante, porque a grande maioria de sua população tenderá a sair ganhadora, o que abre a possibilidade de se alcançar razoável coesão social.

(6) E prosperaram, porque cumpriram a função de promover interesses concretos de acumulação de capital, capitaneados por empresas privadas, multinacionais e nacionais, por empresas estatais e governos e por lobbies variados, envolvendo empresários, políticos e tecnocratas. Leia-se, por exemplo, o livro de Luciano Martins (1976) um fascinante estudo político sobre a criação da Companhia Siderúrgica Nacional, a Petrobrás, o BNDES e a indústria automobilística - infelizmente, ainda não traduzido em Português. 


\subsection{Primeiro motor do desenvolvimento: produção e consumo de massa}

Nos últimos anos, ocorreu no país uma forte expansão do mercado de consumo de massa, segundo mostram inequívocas evidências.

São quatro, ao que tudo indica, as principais causas: i) rápido aumento na massa salarial, por volume de emprego e elevação dos rendimentos do trabalho; ii) transferências de renda à população pobre, por efeito de políticas sociais como o impacto do aumento do salário mínimo sobre as pensões e o "Bolsa Família"; iii) estabilidade ou queda nos preços dos bens industriais de consumo popular por valorização cambial e por importação de bens da China e da Ásia; iv) forte ampliação do crédito ao consumo e acesso da população de baixa renda ao mesmo ${ }^{7}$.

A discussão brasileira sobre a adoção de um modelo de crescimento com melhoria distributiva pela via da produção e consumo de massa remonta aos anos 1960, quando foi inaugurada por Celso Furtado ${ }^{8}$.

O modelo de produção e consumo de massa representa extraordinária oportunidade para o Brasil, devido ao potencial de rendimentos de escala proporcionados pelas dimensões de seu mercado interno e ao fato de que os bens de consumo de massa são produzidos por estruturas produtivas e empresariais modernas, afeitas ao progresso técnico e ao aumento de produtividade.

Sob o ponto de vista meramente teórico, é possível afirmar que o modelo de produção e consumo de massa opera de acordo com o estabelecimento do seguinte

(7) A sustentabilidade desses elementos causadores do consumo de massa é tema controvertido. O autor do presente texto considera que, daqui por diante, somente um crescimento rápido da economia, do emprego e massa salarial poderá dar curso à ampliação do consumo de massa e compensar a necessidade de alteração de políticas no que se refere à ampliação do endividamento familiar e ao recurso a taxas de câmbio apreciadas.

(8) Os Episódios mais importantes da trajetória desse projeto no pensamento desenvolvimentista são: i) Furtado (1966) argumenta que a estrutura distributiva teria de ser modificada para provocar uma alteração no perfil de demanda que reorientasse a estrutura produtiva na direção de uma elevação na intensidade do emprego de mão de obra. Enquanto isso não ocorresse, haveria uma tendência à concentração de renda e à estagnação por insuficiência de demanda e retornos decrescentes de escala; ii) Alguns anos depois, Tavares e Serra (1973), Conceição Tavares e José Serra (1972) argumentariam que a concentração de renda era perversa socialmente, mas funcional ao crescimento; iii) Gradualmente, vários economistas, como por exemplo, Wells (1975) passariam a prover evidências de que uma redistribuição de renda tenderia a implicar aumento na demanda de bens dos setores modernos da economia mais que proporcional aos ganhos de renda. A principal implicação analítica dessas evidências era a de que uma melhoria na distribuição de renda não implicaria alteração radical na estrutura produtiva. A questão da adaptação do perfil da oferta a um perfil de demanda com menor concentração de renda recebia, com a constatação, um importante ingrediente novo; iv) Castro (1989) percebeu o alcance das evidências e argumentou que havia condições para que o Brasil ingressasse em uma fase de expansão "horizontal" da estrutura produtiva moderna já existente, por meio da extensão às classes mais pobres do acesso aos bens de consumo modernos. A estratégia de construção do futuro do Brasil deveria basear-se na possibilidade de expansão nos segmentos modernos, com fortes ganhos de produtividade por economias de escala, devido ao tamanho do mercado interno brasileiro. O Partido dos Trabalhadores aproveitou o projeto em documentos da campanha eleitoral de 2002 e, durante o governo Lula, foi apresentado com destaque no Plano Plurianual 2004-2007 e mencionado nos Planos Plurianuais 2008-2011 e 20022015 (Brasil, Ministério do Planejamento, Orçamento e Gestão, 2003, 2007 e 2011). 
círculo virtuoso: i) o aumento do consumo provoca a expansão dos investimentos, que se traduzem em aumento de produtividade e competitividade pelas vias de mais equipamentos por trabalhador, conhecimento, aprendizado e inovação e economias de escala (da produção em massa); ii) a elevação da produtividade transmite-se equilibradamente a lucros e rendimentos das famílias trabalhadoras pelo aumento de salários, redução dos preços dos bens e serviços e aumento dos gastos sociais; iii) esses rendimentos transformam-se em consumo popular continuamente ampliado; iv) essa ampliação provoca a expansão dos investimentos.

O modelo de produção e consumo de massa representa a grande oportunidade que o Brasil (ainda) dispõe de confirmar seu considerável parque industrial e fazê-lo avançar por meio dos encadeamentos produtivos da produção de bens finais de consumo popular, inclusive daqueles de maior intensidade tecnológica, portadores do futuro, como são os casos da indústria eletrônica, parte da indústria química e dos setores de bens de capital. O modelo possui também a extraordinária virtude de ser estimulado por uma integração virtuosa entre crescimento e melhoria distributiva da renda, como se verificou no pós-guerra em vários países desenvolvidos. Trata-se de uma estratégia de desenvolvimento ao mesmo tempo social e nacional.

O modelo, porém, para que funcione, requer bem mais do que o consumo de massa. Exige também que se realize a produção no país de parte importante dos bens finais e de seus principais encadeamentos produtivos, "para frente" e "para trás".

No atual caso brasileiro, ainda que o tema não tenha sido objeto de pesquisa, é de se supor que os benefícios da ampliação do consumo de massa sobre a produção e a produtividade de alimentos, assim como os de serviços em geral- exceto, talvez, os de maior sofisticação tecnológica - estejam sendo importantes. São segmentos pouco expostos à concorrência internacional, ou detentores de estupenda competitividade internacional. $\mathrm{O}$ essencial à operação do modelo, entretanto, ainda não está claro. Nos casos dos bens industriais expostos à concorrência mundial e fundamentais para o êxito a longo prazo da produtividade e das contas externas, pergunta-se: será que a produção em massa estimulada pelo consumo de massa será feita no país ou teremos consumo de massa no Brasil e produção em massa na China?

A pergunta é relevante, por duas razões. Primeiro, somente a realização da produção em massa no país é que permite o aumento de rendimentos de escala, progresso técnico e consequente maior espaço para elevação de salários. Segundo, a perpetuação de importações massivas de bens industriais, em prejuízo da produção doméstica, pode implicar o restabelecimento de problemas de estrangulamento de balança de pagamentos a médio ou longo prazo. 
$\mathrm{Na}$ última década, houve desfavorável evolução da produtividade e da balança comercial do setor industrial no Brasil ${ }^{9}$. Não é difícil concluir que existe grande assimetria entre, por um lado, a agressiva forma como a China vem promovendo suas exportações industriais, mantendo a taxa de câmbio real depreciada apesar de forte aumento da taxa de inovação e redução de custos de sua indústria; e, por outro lado, a forma como o Brasil vem atuando, mantendo apreciada a taxa real de câmbio apesar de não conseguir fazer crescer a produtividade industrial.

\subsection{Segundo motor do desenvolvimento: uso de recursos naturais}

O Brasil tem abundância de recursos naturais - terra, água, sol, energia. Nesta era de forte expansão do consumo asiático isto pode, em princípio, implicar espetaculares ganhos na renda brasileira a médio e longo prazos para o país. $\mathrm{O}$ progresso técnico nos setores associados a novas fontes de energia elétrica, na extração de petróleo em águas profundas e muito profundas e na produção de etanol, os avanços que o Brasil tem conquistado no domínio da tecnologia agrícola na região dos cerrados e o imenso campo de inovação representado por sua extraordinária biodiversidade são apenas alguns exemplos do potencial de afirmação tecnológica brasileira no mundo em áreas de produção e inovação promissores a longo prazo.

Para que, todavia, isso ocorra, as atividades baseadas em recursos naturais não podem ser meros enclaves de onde saíam as matérias-primas sem deixar rastro de emprego, progresso técnico e bem-estar social ${ }^{10}$.

A propósito, vale observar que, enquanto na fase agroexportadora brasileira anterior aos anos 1930, a agricultura (café, açúcar, cacau etc.) gerava muito emprego e a expressão "enclave" prestava-se essencialmente à caracterização da atividade mineira de outros países, na agricultura moderna a geração direta de emprego é escassa. A atividade encontra-se profundamente mecanizada e, além disso, os modernos corredores de exportação tendem a orientar-se para exportar bens in natura, com escasso processamento industrial local.

Para que os ganhos potenciais gerados pela crescente demanda mundial pelas matérias-primas brasileiras sejam aproveitados, é necessário produzir no país parte considerável das máquinas, sementes e demais insumos agrícolas e que aqui se adicione valor em toda a cadeia alimentar. O raciocínio para os demais recursos naturais é semelhante: é necessário que aqui se produzam boa parte dos equipamentos e serviços de alta densidade tecnológica para petróleo e produção de etanol; que o mesmo seja feito para geração, transmissão e distribuição de energia

(9) Ver, por exemplo, Squeff (2012) sobre produtividade e Oreiro e Feijó (2010) e Carcanholo (2010), sobre balança comercial.

(10) A respeito, ver, por exemplo, o excelente artigo de Perez (2010) sobre uma estratégia de desenvolvimento para a América Latina, com base no uso de recursos naturais. 
elétrica, sendo a ciência, tecnologia e inovação correspondentes à biodiversidade do território brasileiro substancialmente produtos da inteligência nacional, e o turismo explorado de maneira adequada.

A agenda nacional relativa aos cuidados necessários a um bom uso dos recursos naturais vai bem além da questão da inovação e dos encadeamentos produtivos gerados a partir da produção primária. Há, pelo menos, outros três desafios a uma estratégia nacional de desenvolvimento derivados da abundância de recursos naturais.

Primeiro, há a ameaça de compra de terra e do acesso à energia e a metais pela China e outras potências mundiais. Se permitido, capitais oriundos das potências mundiais tentarão comprar todo o território nacional, do Oiapoque ao Chuí. A propósito, será interessante estudar a forma como os países desenvolvidos lidam com propriedade da terra e acesso à energia e demais recursos naturais estratégicos localizados nos respectivos territórios, de maneira a verificar a conveniência de replicar suas políticas no Brasil.

Segundo, a pressão que o aumento do uso de recursos naturais exerce sobre a natureza e a sustentabilidade ambiental precisa ser controlada. A complexa agenda de desenvolvimento sustentável tende a tornar-se ainda maior e de mais difícil administração, daqui para frente.

O terceiro desafio é o da absorção pelo setor privado ou por interesses públicos menores dos ganhos originados pela valorização dos preços dos bens e serviços baseados em recursos naturais. A propósito, é de se esperar uma boa solução para o petróleo do "Pré-Sal" e de se lamentar que a Vale tenha sido privatizada sem um resguardo mínimo dos interesses nacionais. Na privatização, deveria ter-se pensado em mais do que simplesmente exportar ferro e gerar lucro para os acionistas da Vale. Valorizações espetaculares de recursos do subsolo deveriam ser prioritariamente empregadas para gerar dividendos à sociedade como educação e inovação. Sua simples absorção por meio de impostos - ao invés de por royalties - é socialmente insatisfatória.

\subsection{Terceiro motor do desenvolvimento: investimentos em infraestrutura}

Os investimentos em infraestrutura são um motor do desenvolvimento, porque movimentam uma quantidade gigantesca de recursos e de emprego, e geram externalidades ao setor privado e à economia como um todo, razões pelas quais têm a responsabilidade de incentivar a expansão do investimento privado.

Como, porém, nos dois outros casos, a potência desse motor depende das atividades que desencadeia em seu entorno. 
Há inovações e encadeamentos demandados pelo investimento em infraestrutura que implicam processos relativamente simples do ponto de vista tecnológico, como a "conteinerização" de cargas ferroviárias, o gerenciamento de dejetos químicos nos projetos de saneamento básico, novos materiais para residências da população pobre etc. Há outras que podem envolver atividades sofisticadas, como a produção de equipamentos para movimentação de terra, de sistemas eletrônicos de comando do trem bala e de metrôs, de sistemas satelitais e equipamentos eletrônicos para monitorar transporte rodoviário e gado etc.

Há, por certo, dúvida sobre a expansão dos investimentos em infraestrutura no Brasil. A série histórica de investimento em infraestrutura mostra que os mesmos caíram consideravelmente a partir da primeira metade dos anos 1980. O único setor de infraestrutura a ter uma expansão considerável foi o de telecomunicações, ciclo que durou cerca de quatro anos.

Nesses últimos anos, porém, ainda que de forma um tanto lenta, os investimentos estão expandindo-se nas diferentes áreas da infraestrutura, inclusive nas quatro de maior peso, ou seja, transportes - interurbanos e urbanos - energia elétrica, habitação/saneamento e telecomunicações. Isso, somado aos vultosos investimentos da Petrobrás, apontam no sentido de uma firme expansão futura do investimento autônomo liderado pelo governo e suas empresas.

As dificuldades de confirmar e acelerar a expansão não são pequenas. Elas passam, como se sabe, por exigências legais sobre preservação ambiental, e por atrair capitais privados a empreendimentos de longo prazo de maturação, riscos e incertezas frequentemente elevadas, mas nem sempre com boas perspectivas de rentabilidade. Passam, também, por dificuldades em abrir maior espaço fiscal ao investimento público sem prejudicar as necessidades das políticas sociais. Há, no entanto, uma série de razões que também conduzem a algum otimismo.

Primeiro, o governo vem fortalecendo sua capacidade de planejamento e execução de obras, por meio dos planos de aceleração do crescimento (PAC).

Segundo, depois de um longo período de precrarização dos serviços de consultoria e de engenharia no país, que ajudaram a travar a expansão dos investimentos no passado, parece estar havendo gradual recuperação nesses serviços.

Terceiro, não menos importante, tem sido restabelecida a capacidade de financiamento de investimento de longa maturação, públicos e privados: i) o aumento considerável da carga fiscal tem dado margem de manobra para abrir espaço para investimentos do setor público; ii) a expansão do capital do BNDES e o retorno à permissão para que financie obras de governos correspondem a uma renovação importante na mobilização de recursos; iii) o mercado de capitais tem sofisticação e dimensão suficientes para financiar investimento de longo prazo, seja exclusivamente 
privados, seja por parcerias público-privadas; iv) no caso de construção residencial, tem sido ampliada a disponibilidade de recursos e condições de financiamento, inclusive para construção de natureza social, com o programa " Minha Casa Minha Vida".

O anterior significa que o país poderá dirigir-se a taxas de investimento viabilizadoras de um crescimento do PIB bem mais rápido do que se observa nos últimos anos - apenas 4\% ao ano em média, entre 2004 e 2011 - e dar continuidade ao recente aumento na taxa de investimento ${ }^{11}$.

O estímulo ao desenvolvimento econômico derivado da realização dos investimentos em infraestrutura não se encerra, porém, com a mera provisão dos serviços que a infraestrutura presta. Potencialmente, ao menos, vai muito além, estendendo-se pela economia como um todo por meio dos efeitos de encadeamento e inovação transmitidos aos demais setores da economia.

\section{Os dois "turbinadores"}

Conforme argumentado nas seções anteriores, cada um dos três motores do investimento pode ser potencializado por dois tipos de "turbinadores".

Primeiro, pelo processo de inovação. Ele diz respeito a novos processos e produtos, seja na viabilização de novas atividades econômicas em cada frente de expansão, seja pela formação no país de encadeamentos produtivos em segmentos tecnologicamente nobres das três frentes de expansão. Segundo, por investimentos nos encadeamentos produtivos tradicionais, não dependentes de maiores inovações.

A formulação de um novo projeto de desenvolvimento brasileiro baseado em inovação e competitividade remonta aos anos 1980, quando foi pensado como candidato natural a dinamizador da economia ao término do processo de industrialização. Como, no entanto, anteriormente observado, na opinião de quem escreve este ensaio inovação não consegue, no caso brasileiro, cumprir a função de frente de expansão per se. O Brasil ainda não possui como motor do investimento a inovação em grande escala, que permanece um privilégio restrito, por enquanto, a alguns países desenvolvidos - e, ao que tudo indica crescentemente também à China, em especial, na produção em massa de bens industriais com custos decrescentes e preços acessíveis a países e consumidores de rendas relativamente baixas.

(11) Graças a uma taxa de expansão anual de $8,8 \%$ nesse mesmo período, o investimento subiu do patamar de cerca de 15 a 16\% do PIB em que se manteve por muitos anos, para cerca de $19 \%$ do PIB em 2010. Há, no entanto, necessidade de que se eleve mais 4 ou 5 pontos percentuais, sem o que o atual período expansivo dificilmente se transformará em um ciclo de desenvolvimento de longo prazo. 
Não significa, porém, ficar parado em matéria de inovação e investimentos em segmentos selecionados de alta intensidade tecnológica. Eles poderão ser responsáveis por turbinar as frentes de expansão que o país possui por três meios.

Primeiro, poderão reforçar a médio e longo prazos a estrutura produtiva já existente nas três frentes de expansão. Considerando-se a velocidade com que o progresso técnico evolui no mundo, tornando-se vital a quase todas as atividades econômicas, a inovação cumprirá a função de permitir a redução de custos e o aumento da competitividade internacional. Segundo, poderão dar lugar ao surgimento de novas atividades, como exemplo aquelas associadas à exploração do "Pré-sal" e ao uso sustentável da biodiversidade. Terceiro, permitirão aproveitar a contribuição potencial dos encadeamentos produtivos acionados pelos três motores nos segmentos tecnologicamente mais nobres, ampliando as cadeias produtivas nos segmentos em que o progresso técnico ocorre com maior velocidade.

Se o esforço científico e tecnológico brasileiro tiver, no futuro, a intensidade desejada, mais à frente a inovação poderá tornar-se um motor do desenvolvimento em si mesma e uma evidência de maturidade e autonomia para crescer da economia brasileira. Desde já, cabe um estudo sistemático quanto aos "nichos" de progresso técnico sobre os quais a política tecnológica do país deveria debruçar-se de maneira a orientar as apostas brasileiras. O modelo das três frentes de expansão pode ajudar o exercício.

Quanto ao restabelecimento de encadeamentos produtivos tradicionais, essa é uma questão a qual requer uma pesquisa baseada na matriz de insumo-produto, permitindo identificar os elos das cadeias produtivas tradicionais que se perderam ou se enfraqueceram e abrir uma reflexão sobre aquelas que ainda possuem ampla competitividade potencial $^{12}$. Uma pesquisa de tal natureza permitiria avaliar, por exemplo, como se comportou o encadeamento setorial das atividades industriais de maior conteúdo tecnológico ao longo do tempo vis-à-vis àquelas mais intensivas em recursos naturais, valendo-se de índices de ligações para frente e para trás. Esse tipo de diagnóstico seria em muito enriquecido se também levasse em consideração a evolução do emprego e investimento.

Trata-se de uma avaliação que, no contexto das atividades produtivas a comporem os três motores de desenvolvimento, permitiria uma reflexão sobre estratégias de desenvolvimento e dinamização da economia por meio de

(12) As Matrizes de insumo-produto (MIPs) são um instrumental poderoso para se avaliar a estrutura produtiva do país, notadamente no que concerne aos encadeamentos produtivos entre as atividades econômicas. Embora as matrizes oficiais mais recentes sejam relativas aos anos de 2000 e 2005, Guilhoto e Sesso Filho (2005) desenvolveram metodologias de cálculo de MIPs anuais com base nas tabelas de recursos e usos calculadas pelo IBGE. Além disso, encontra-se em curso uma nova pesquisa, coordenada pelo Professor Fabio Freitas, no âmbito de um convênio entre o IE/UFRJ e o Ipea. 
fortalecimento da indústria e diversificação da atividade produtiva, com ênfase na questão das "fortalezas" e "debilidades" da estrutura produtiva (elos "fracos" e "elos fortes”). Significa permitir a identificação mais acurada da estratégia de desenvolvimento econômico aqui proposta ${ }^{13}$.

\section{A modo de conclusão}

Este ensaio foi escrito com a pretensão de ajudar a organizar, conceitualmente, o debate brasileiro sobre desenvolvimento. $\mathrm{O}$ desenho de estratégia desenvolvimento proposto está baseado nas ideias de existência de três frentes de expansão (consumo de massa, recursos naturais e infraestrutura) e de relevância de se acionar dois "turbinadores" desses motores do desenvolvimento (inovação tecnológica e encadeamentos produtivos tradicionais). Argumentou-se que a fórmula assenta-se em um padrão viável de expansão econômica a longo prazo - tal como, no passado, ocorreu com o processo de industrialização.

A tradição estruturalista cepalina de Raúl Prebisch e Celso Furtado faria, provavelmente, alguns questionamentos básicos a essa formulação. Perguntaria, por exemplo, o que o Estado está fazendo para planejar e garantir a operação satisfatória dos três motores do desenvolvimento. Em sua atual fase neoestruturalista, estenderia a pergunta ao foco dos investimentos em segmentos produtivos de alta densidade tecnológica e em inovação nas empresas atuantes no país. Perguntaria, ainda, se a transformação ensejada pela dinâmica dos três motores conseguiria eliminar a profunda heterogeneidade estrutural ainda existente e em que prazos.

Provavelmente, recomendaria também que, no atual período de bonança em relação a reservas externas e preços de bens intensivos em recursos naturais, o país não cochile e busque uma autonomização externa mais definitiva fazendo isso por meio da diversificação produtiva e exportadora e da incorporação do progresso técnico na indústria e restante da estrutura produtiva nacional.

Por certo, lembraria ainda que há elementos críticos de qualquer processo de desenvolvimento ausentes do ensaio como educação, políticas sociais, integração regional e harmonia territorial, sustentabilidade ambiental e reformas institucionais.

Por fim, e não menos importante, provavelmente reconheceria também que a agenda nacional de desenvolvimento encontra-se renovada. Atentaria para o fato de que as oportunidades e desafios são gigantescos, tendo de saber enfrentá-los.

(13) O autor do presente ensaio está fazendo em conjunto com os economistas Antonio Candido Daguer Moreira, da FINEP e Gabriel Squeff, do IPEA, na perspectiva das três frentes de expansão, um estudo sobre os dois "turbinadores", ou seja, as inovações e encadeamentos produtivos. Isso está sendo realizado no âmbito do um projeto do IPEA sobre estratégias de desenvolvimento em que também se insere este ensaio. 


\section{Bibliografia}

BIELSCHOWSKY, R. Pensamento econômico brasileiro - o ciclo ideológico do desenvolvimentismo. Rio de janeiro: Contraponto, 2005. Ipea, 2002.

(Coord.). Investimento e reforma no Brasil nos anos 1990, cap. 2. Brasília: Cepal-

MUSSI, Carlos, C. El pensamiento desarrollista en Brasil: 1930-1964 y anotaciones sobre 1964-2005. In: BRASIL y Chile, una mirada hacia América Latina. Santiago de Chile: RIL Editores, 2006.

BRASIL. MPOG. Ministério do Planejamento, Orçamento e Gestão. Plano Plurianual 20042007. Brasília: MPOG, 2003.

Plano Plurianual 2008-2011. Brasília: MPOG, 2007.

. Plano Plurianual 2012-2015. Brasília: MPOG, 2011.

BRASIL. Presidência da República. Programa de Aceleração do Crescimento, PAC. Brasília: 2007.

BRASIL. Ministério do Desenvolvimento, Indústria e Comércio. Programa de Desenvolvimento Produtivo, PDP. Brasília: 2008.

BRASIL. Ministério do Desenvolvimento, Indústria e Comércio. Brasil Maior. Brasília: MDIC, 2011.

Política industrial, tecnológica e de comércio exterior, PITCE. Brasília: 2003.

BRASIL. Ministério da Fazenda. Política econômica e reformas estruturais. Brasília: Secretaria de Política Econômica (SPE) do Ministério da Fazenda (MF), 2003.

BRESSER-PEREIRA, L. C. Novo desenvolvimentismo: uma proposta para a economia do Brasil. São Paulo: Nueva Sociedad, edição especial em português, 2010.

CARCANHOLO, M. D. Inserção externa e vulnerabilidade da economia brasileira no governo Lula. In: MAGALHÃES, J. P. A. et al. Os anos Lula: contribuições para um balanço crítico. Ed. Garamond, 2010.

CASTRO, A. B. Consumo de massas e retomada do crescimento - sugestões para uma estratégia. Banco do Brasil, 1989. Mimeo.

Renegade development: rise and demise of state-led development in Brazil. In:

SMITH, W. et al. (Org.). Democracy, markets and structural reform in Latin America. Transaction Publishers, 1993.

FURTADO, C. Subdesenvolvimento e estagnação da América Latina. Rio de Janeiro: Civilização Brasileira, 1966.

GIMENEZ, D. M.; CARDOSO, J. C. Planejamento e desenvolvimento: considerações à luz de documentos do governo brasileiro entre 2003 e 2010. Brasília: Ipea, jan. 2012. (Texto para Discussão, n. 1690). 
GUILHOTO, J. J. M.; SESSO FILHO, U. A. Estimação da matriz insumo-produto à partir de dados preliminares das contas nacionais. Economia Aplicada, v. 9, n. 2, p. 277-299, 2005.

KALDOR, N. The role of increasing returns, technical progress and cumulative causation in the theory of international trade and economic growth in the United Kingdom. In: TARGETTI, F.; THIRLWALL, A. (Org.). The essential Kaldor. Inglaterra: Duckworth, 1989.

KEYNES (1973). Teoria do emprego, do juro e da moeda. São Paulo: Editora Atlas, 1982.

MARTINS, L. Pouvoir et development economique. Paris: Anthropos, 1976.

OREIRO, J. L.; FEIJÓ, C. Desindustrialização: causas, efeitos e o caso brasileiro. Revista de Economia Política, v. 30, n. 2 (118), abr./jun. 2010.

PARTIDO dos Trabalhadores. Programa de Governo, Coligação Lula Presidente. São Paulo: PT, 2002.

. Programa de Governo, Coligação Lula Presidente. São Paulo: PT, 2006.

PEREZ , Carlota. Dinamismo tecnológico e inclusión social en América Latina: una estrategia de desarrollo productivo basada em los recursos naturales. Revista de la Cepal, n. 100 , abr. 2010.

PINTO, Aníbal. Notas sobre los estilos de desarrollo en América Latina. Revista de la Cepal, Santiago de Chile, n. 1, 1976.

TAVARES, M. C.; SERRA, J. Além da estagnação. In: DA SUBSTITUIÇÃO de importações ao capitalismo financeiro. Rio de Janeiro: Zahar, 1973.

SICSU, J.; DE PAULA, L. F.; MICHEL, R et al. Novo desenvolvimenismo: um projeto nacional de desenvolvimento com equidade social. Rio de Janeiro: Manolo, 2005.

SQUEFF, G. Desindustrialização, luzes e sombras no debate brasileiro. Brasília: Ipea, 2012. (Texto para Discussão, n. 1747).

WELLS, J. Distribuição de rendimentos, crescimento e a estrutura de demanda no Brasil na década de 60. In: TOLIPAN, Ricardo; TINELLI, Arthur. A controvérsia sobre distribuição de renda e desenvolvimento. Rio de Janeiro: Zahar Editores, 1975. 